\title{
Morfologi dan variasi morfometrik lebah tanpa sengat di Kepulauan Maluku, Indonesia
}

\author{
Morphology and morphometric variation of stingless bees in the \\ Moluccas, Indonesia
}

\author{
Yofian Anaktototy ${ }^{1}$, Windra Priawandiputra ${ }^{1}$, Tiara Sayusti ${ }^{1}$, \\ Jacobus S. A. Lamerkabel ${ }^{2}$, Rika Raffiudin ${ }^{1}{ }^{*}$ \\ ${ }^{1}$ Departemen Biologi, Fakultas Matematika dan Ilmu Pengetahuan Alam, IPB University \\ Jalan Agatis, Kampus IPB Dramaga, Dramaga 16680 \\ ${ }^{2}$ Program Studi Agroteknologi, Fakultas Pertanian, Universitas Pattimura \\ Jalan Ir M Putuhena Poka, Ambon 97233
}

(diterima Juli 2020, disetujui Februari 2021)

\begin{abstract}
ABSTRAK
Lebah tanpa sengat tersebar luas di wilayah tropis termasuk Indonesia dan tercatat tiga spesies lebah tanpa sengat di Maluku. Penelitian ini bertujuan untuk mengeksplorasi spesies lebah tanpa sengat dan persebarannya di Kepulauan Maluku, yaitu di Pulau Seram, Ambon, Haruku, Saparua, dan Nusalaut, serta membandingkan variasi morfometrik lebah tanpa sengat antar spesies dan antar individu dari spesies yang sama pada setiap pulau serta antar pulau. Sampel lebah diidentifikasi berdasarkan morfologi dengan 12 parameter morfometrik. Penelitian ini berhasil mengidentifikasi dua spesies lebah tanpa sengat, yaitu Tetragonula fuscobalteata (Cameron) dan T. sapiens (Cockerell). T. fuscobalteata merupakan catatan baru lebah tanpa sengat di Kepulauan Maluku dan lebah ini secara nyata memiliki pengukuran morfometrik lebih rendah daripada T. sapiens ( $\mathrm{P}$ $<0,001)$. Berdasarkan analisis ordinasi non-metric multidimensional scaling (NMDS), gabungan 12 parameter morfometrik antara T. fuscobalteata dan T. sapiens menunjukkan perbedaan yang nyata. Parameter morfometrik T. fuscobalteata sangat bervariasi antar pulau kecuali satu parameter morfometrik (lebar gena) yang tidak nyata antar pulau $(\mathrm{P}>0,05)$. Hal menarik lain berdasarkan analisis NMDS, koloni T. fuscobalteata di Ambon, Haruku, Saparua, dan Nusalaut sebagian besar membentuk kelompok, namun di Pulau Seram lebah tersebar dengan variasi morfometrik yang tinggi. T. sapiens ditemukan di tiga pulau, yaitu Seram, Ambon, dan Haruku. Lebar toraks, mesonotum dan panjang propodeum T. sapiens berbeda nyata di antara tiga pulau $(\mathrm{P}<0,001)$. Hasil penelitian ini berkontribusi dalam menambah catatan penemuan persebaran baru T. fuscobalteata dan T. sapiens di Kepulauan Maluku dan menunjukkan variasi parameter morfometrik pada spesies lebah tanpa sengat antar pulau di Maluku.
\end{abstract}

Kata kunci: biogeografi, kepulauan, Tetragonula fuscobalteata, Tetragonula sapiens, Wallacea

\begin{abstract}
Stingless bees are widely distributed in tropical regions including Indonesia, and currently three species of stingless bee have been recorded in the Moluccas. The aims of this study were to explore the species and distribution of stingless bees in the five islands in the Moluccas (Seram, Ambon, Haruku, Saparua, and Nusalaut island) and compare the morphometric variations of stingless bees within and among islands. The samples of stingless bees were identified based on twelve morphological characters, resulting in two species of Tetragonula fuscobalteata (Cameron) and T. sapiens. (Cockerell). T. fuscobalteata found to be a new record in the Moluccas, and showed significantly lower morphometric parameters compared to those of T. sapiens $(\mathrm{P}<0.001)$. Based on
\end{abstract}

\footnotetext{
*Penulis korespondensi: Rika Raffiudin. Departemen Biologi, Fakultas Matematika dan Ilmu Pengetahuan Alam, IPB University Jalan Agatis, Kampus IPB Dramaga 16680, Tel/Faks: 0251-8622833, Email: rika.raffiudin@apps.ipb.ac.id 
non-metric multidimensional scaling (NMDS) analysis, the combination of twelve morphometric parameters between T. fuscobalteata and T. sapiens were significantly different. Almost all morphometric parameters of $T$. fuscobalteata showed highly varied among islands, except the width of gena of this stingless bees. T. fuscobalteata from Ambon, Haruku, Saparua, and Nusalaut were mostly clustered based on NMDS analysis, while those from Seram show high variations. This study found T. sapiens in three different islands, Seram, Ambon, and Haruku. Width of thorax, mesonotum, and propodeum length of $T$. sapiens were significantly different among these three islands $(\mathrm{P}<0.001)$. This study has contributed to the new distribution data of $T$. fuscobalteata and $T$. sapiens in the Moluccas and showed variation of morphometric parameters of the two stingless bee species among islands in the Moluccas.

Key words: biogeography, islands, Tetragonula fuscobalteata, Tetragonula sapiens, Wallacea

\section{PENDAHULUAN}

Lebah tanpa sengat (Meliponini) merupakan serangga sosial yang tersebar di daerah-daerah tropis (Roubik 1989). Keanekaragaman spesies lebah tanpa sengat di Indonesia adalah sebanyak 46 spesies dengan sebaran di beberapa pulau besar, seperti Sumatra, Jawa, Timor, Borneo, Sulawesi, Kepulauan Maluku, dan Irian Jaya (Kahono et al. 2018). Kepulauan Maluku terletak di antara benua Australia dan Pulau Banda yang berperan penting sebagai penyumbang daratan bagi wilayah Wallacea dengan sebaran hewan yang berbeda dan beragam (Lohman et al 2011; Wikramanayake et al. 2001).

Pulau Seram dan pulau-pulau kecil disekitarnya (Pulau Ambon, Haruku, Saparua, dan Nusalaut) merupakan bagian dari Kepulauan Maluku dan berasal dari patahan lempeng dari wilayah utara sampai barat Australia yang muncul pada dua juta tahun yang lalu (Hamilton 1979). Seram merupakan pulau terbesar di antara keempat pulau lainnya dengan luas $10.680 \mathrm{~km}^{2}$. Pulau dengan luas terkecil adalah Nusalaut dengan luas $34 \mathrm{~km}^{2}$ (BPS Maluku 2015). Spesies lebah tanpa sengat yang tercatat dari wilayah Australia dan Kepulauan Maluku adalah Tetragonula clypearis (Friese) dan T. sapiens (Cockerell) (Dollin et al. 1997). Spesies lebah tanpa sengat lainnya adalah T. laeviceps (Smith) yang ditemukan di Maluku (Kahono et al. 2018) dan juga Pulau Aru (Smith 1859) yang masuk ke dalam lempeng IndoAustralia (Patmawidjaya \& Subagyo 2014). Tercatat bahwa spesies lebah tanpa sengat di Maluku sebanyak 3 spesies (Dollin et al. 1997; Rasmussen 2008; Kahono et al. 2018).

Identifikasi lebah tanpa sengat dapat dilakukan dengan pendekatan morfologi dan morfometrik, misalnya membandingkan panjang ukuran tubuh, perbedaan proporsi warna tubuh, komposisi rambut pada bagian tubuh tertentu serta tungkai (Sakagami et al. 1990; Azizi et al. 2020). Beberapa karakter morfologi untuk identifikasi lebah tanpa sengat adalah karakter tibia belakang, basitarsus belakang, jarak malar, mandibula, kepala, clypeus, propodeum, mesoscutum, mesoscutellum, antena, mata, gena, sayap depan, venasi sayap, hamuli, dan warna tubuh (kepala, clypeus, toraks, abdomen, tegula, sayap) (Sakagami et al. 1990; Azizi et al. 2020). Analisis variasi venasi sayap untuk melihat kekerabatan antar spesies lebah tanpa sengat merupakan salah satu penelitian terkait variasi morfometrik lebah tanpa sengat (Laksono et al. 2020). Pendekatan morfometrik juga dilakukan untuk melihat perbandingan antar spesies lebah tanpa sengat di Pulau Belitung antara spesies Heterotrigona itama (Cockerell), T. laeviceps, dan T. fuscobalteata (Cameron) (Azizi et al. 2020).

Selain itu, karakter lubang sarang dan cara bersarang juga dapat digunakan untuk membedakan spesies lebah tanpa sengat (Roubik 1983). Tipe lubang sarang menjadi karakter untuk mengidentifikasi beberapa spesies lebah tanpa sengat asal Sulawesi, antara lain Wallacetrigona incisa (Sakagami \& Inoue) (celah longitudinal), $T$. sapiens, dan T. fuscobalteata (corong pendek dan elips), serta T. clypearis (corong pendek dan tidak beraturan) (Sayusti et al. 2021).

Penelitian terkait morfologi dan morfometrik lebah tanpa sengat belum banyak dilakukan di Kepulauan Maluku. Penelitian ini bertujuan untuk mengeksplorasi (1) spesies lebah tanpa sengat dan persebarannya di Kepulauan Maluku, yaitu di Pulau Seram dan pulau-pulau kecil disekitarnya: Pulau Ambon, Haruku, Saparua, dan Nusalaut; dan (2) variasi morfometrik lebah tanpa sengat 
antar spesies dan antar individu dari spesies yang sama pada setiap pulau dan antar pulau.

\section{BAHAN DAN METODE}

\section{Lokasi studi}

Lokasi sampling lebah tanpa sengat adalah di lima pulau di Kepulauan Maluku, yaitu Pulau Seram (PSe), Ambon (PA), Haruku (PH), Saparua (PSa), dan Nusalaut (PN) dengan masing-masing pulau terdiri atas tiga desa (Tabel 1). Setiap lokasi koloni lebah tanpa sengat ditandai titik koordinat menggunakan global positioning system (GPS) Garmin Etrex 10.

\section{Koleksi lebah tanpa sengat}

Seluruh koloni yang dikoleksi berasal dari tempat bersarang yang berbeda sekitar wilayah 15 desa (Tabel 1). Sampel lebah tanpa sengat dari desa Waesamu (PSe) dan desa Paperu (PSa) diambil dari sarang bambu pada meliponikultur dengan koloni yang berasal dari desa setempat. Pengambilan lebah juga dilakukan pada tempat bersarang lebah tanpa sengat lainnya, yaitu celah batu, dinding, dan kayu.

Koleksi lebah tanpa sengat kasta pekerja dilakukan dengan menggunakan perangkap plastik yang diletakkan di depan lubang sarang. Sarang bagian luar diketuk-ketuk hingga lebah keluar dan terperangkap di dalam plastik. Selanjutnya, lebah diawetkan dalam tabung berisi alkohol.

\section{Identifikasi sampel dan pengukuran karakter morfometrik}

Sampel lebah diidentifikasi berdasarkan kunci identifikasi Sakagami et al. (1990) yang umum digunakan untuk identifikasi lebah tanpa sengat di Indonesia terutama di Sumatera. Proses verifikasi dilanjutkan menggunakan pencocokan karakter pada kunci dikotom lebah tanpa sengat asal Sulawesi dan Maluku berdasarkan Smith (2012) dan Dollin et al. (1997).

Berdasarkan kunci identifikasi Sakagami et al. (1990) karakter-karakter yang diamati adalah karakter tibia belakang, basitarsus belakang, jarak malar, mandibula, kepala, clypeus, propodeum, mesoscutum, mesoscutellum, antena, mata, gena, sayap depan, venasi sayap, hamuli, dan warna tubuh (kepala, clypeus, toraks, abdomen, tegula, sayap). Karakter lebah tanpa sengat berdasarkan kunci identifikasi Smith (2012) adalah karakterkarakter yang diklasifikasikan berdasarkan ukuran, proporsi warna tubuh yang dominan, karakter rambut-rambut yang terdapat pada bagian mesonotum, karakter warna rambut-rambut yang terdapat pada tibia belakang, serta warna tergit pada bagian abdomen. Karakter-karakter lebah tanpa sengat berdasarkan Dollin et al. (1997) adalah karakter ukuran jarak malar, ukuran flagelomer segmen kedua, karakter rambut yang menutupi, pola rambut (bands) yang memisahkan bagian glaborous (bagian interspace) pada mesoscutum, ukuran tubuh, serta panjang sayap dengan tegula (PSd).

Setiap sampel yang sudah diidentifikasi selanjutnya diukur berdasarkan 12 karakter morfometrik, yaitu (1) panjang tubuh (PT), (2) lebar toraks (LT), (3) lebar flagelomer ke-2 (LFd), (4) lebar jarak antara kedua mata (LJM), (5) lebar gena (LG), (6) jarak malar (JM), (7) panjang mesonotum (PM), (8) panjang propodeum (PP), (9) panjang sayap depan (PSd), (10) panjang sayap belakang (PSb), (11) lebar tibia belakang (LTb), dan (12) lebar basitarsus belakang (LBb). Pengamatan karakter morfologi dan pengukuran morfometrik sampel lebah tanpa sengat menggunakan mikroskop stereo (Olympus) SZ-61 dan Optilab 2.2 dengan perbesaran $4,5 \mathrm{x}$ untuk semua karakter kecuali panjang tubuh menggunakan perbesaran 2,5x. Pengukuran 12 karakter lebah tanpa sengat dilakukan menggunakan Image Raster software versi 3.0 (Miconos 2021). Sampel yang diukur sebanyak lima individu untuk setiap koloni dengan total 45 koloni ( $\mathrm{n}=225$ individu).

\section{Analisis data}

Perbandingan 12 karakter morfometrik antara dua spesies lebah tanpa sengat diuji menggunakan uji Mann-Whitney. Uji Kruskal-Wallis digunakan untuk membandingkan 12 karakter morfometrik dari spesies lebah yang sama antar pulau. Analisis non-metric multidimensional scaling (NMDS) berdasarkan indeks Euclidean digunakan untuk membandingkan pola kesamaan 12 karakter morfometrik yang dimiliki antar spesies lebah dan antar pulau pada masing-masing spesies lebah. Analysis of similarity (ANOSIM) digunakan untuk membuktikan secara nyata dari perbandingan kesamaan antar spesies dan antar 
pulau pada masing-masing spesies lebah tanpa sengat. Seluruh data dan analisis tersebut diolah menggunakan program analisis data statistik PAST (Paleontological Statistic) versi 3.0 (Hammer et al. 2009).

\section{HASIL}

\section{Dua spesies lebah tanpa sengat asal Maluku}

Total 45 koloni lebah tanpa sengat yang dikoleksi di lima pulau teridentifikasi ke dalam dua spesies dari Genus Tetragonula, yaitu $T$. fuscobalteata (40 koloni) dan T. sapiens (5 koloni)
(Tabel 1, Gambar 1, dan Gambar 2). Perbedaan karakteristik morfologi $T$. fuscobalteata dan T. sapiens dirangkum pada Tabel 2. Karakter lebah pekerja T. sapiens dari 5 koloni $(\mathrm{n}=25$ individu) memiliki warna tubuh hitam dan lebih gelap daripada lebah pekerja $T$. fuscobalteata. Abdomen tergit 1-6 pada T. sapiens berwarna hitam, sedangkan tergit 1-2 pada T. fuscobalteata berwarna kekuningan atau coklat terang, dan tergit berwarna 3-6 coklat gelap. Scutal glabrous (G) T. fuscobalteata terlihat sangat jelas (Gambar 1C), sedangkan scutal glabrous (G) T. sapiens kurang terlihat jelas (Gambar 2B). Karakter morfologi $T$. fuscobalteata di Kepulaun Maluku dari studi ini

Tabel 1. Lokasi pengambilan sampel dan jumlah koloni lebah tanpa sengat di lima pulau di Kepulauan Maluku

\begin{tabular}{|c|c|c|c|c|c|c|}
\hline Desa & Koloni & Titik GPS & $\begin{array}{l}\text { Ketinggian } \\
\quad(\mathrm{m} \mathrm{dpl})\end{array}$ & $\begin{array}{l}\text { Nomor } \\
\text { koloni }\end{array}$ & Spesies & $\begin{array}{c}\text { Total } \\
\text { koloni }\end{array}$ \\
\hline \multicolumn{7}{|c|}{ A. Pulau Seram (PSe) } \\
\hline \multirow[t]{4}{*}{ Nuruwe } & 1 & $03^{\circ} 14.344^{\prime} \mathrm{S} 128^{\circ} 17.938^{\prime} \mathrm{E}$ & 10 & Koloni 1 & T. fuscobalteata & 1 \\
\hline & 2 & $03^{\circ} 14.333^{\prime} \mathrm{S} 128^{\circ} 17.886^{\prime} \mathrm{E}$ & 7 & Koloni 2 & T. fuscobalteata & 1 \\
\hline & 3 & $03^{\circ} 14.266^{\prime} \mathrm{S} 128^{\circ} 17.909^{\prime} \mathrm{E}$ & 17 & Koloni 3 & T. fuscobalteata & 1 \\
\hline & 4 & $03^{\circ} 14.274^{\prime} \mathrm{S} 128^{\circ} 17.937^{\prime} \mathrm{E}$ & 14 & Koloni 4 & T. fuscobalteata & 1 \\
\hline \multirow[t]{4}{*}{ Waesamu } & 5 & $03^{\circ} 16.411^{\prime} \mathrm{S} 128^{\circ} 18.843^{\prime} \mathrm{E}$ & 5 & Koloni 5 & T. sapiens & 1 \\
\hline & 6 & $03^{\circ} 16.405^{\prime} \mathrm{S} 128^{\circ} 18.855^{\prime} \mathrm{E}$ & 16 & Koloni 6 & T. fuscobalteata & 1 \\
\hline & 7 & $03^{\circ} 16.430^{\prime} \mathrm{S} 128^{\circ} 18.854^{\prime} \mathrm{E}$ & 5 & Koloni 7 & T. fuscobalteata & 1 \\
\hline & 8 & $03^{\circ} 16.525^{\prime} \mathrm{S} 128^{\circ} 18.758^{\prime} \mathrm{E}$ & 4 & Koloni 8 & T. fuscobalteata & 1 \\
\hline Kamarian & $9-13$ & $03^{\circ} 26.411^{\prime} \mathrm{S} 128^{\circ} 25.608^{\prime} \mathrm{E}$ & 6 & Koloni 9-13 & T. fuscobalteata & 5 \\
\hline \multicolumn{7}{|c|}{ B. Pulau Ambon (PA) } \\
\hline \multirow[t]{3}{*}{ Hattu } & 14 & $03^{\circ} 43.748^{\prime} \mathrm{S} 128^{\circ} 02.954^{\prime} \mathrm{E}$ & 10 & Koloni 1 & T. fuscobalteata & 1 \\
\hline & 15 & $03^{\circ} 43.699^{\prime} \mathrm{S} 128^{\circ} 02.889^{\prime} \mathrm{E}$ & 19 & Koloni 2 & T. sapiens & 1 \\
\hline & 16 & $03^{\circ} 43.644^{\prime} \mathrm{S} 128^{\circ} 02.770^{\prime} \mathrm{E}$ & 18 & Koloni 3 & T. fuscobalteata & 1 \\
\hline \multirow[t]{4}{*}{ Airlouw } & 17 & $03^{\circ} 46.318^{\prime} \mathrm{S} 128^{\circ} 08.097^{\prime} \mathrm{E}$ & 10 & Koloni 4 & T. sapiens & 1 \\
\hline & 18 & $03^{\circ} 46.278^{\prime} \mathrm{S} 128^{\circ} 08.099^{\prime} \mathrm{E}$ & 9 & Koloni 5 & T. fuscobalteata & 1 \\
\hline & 19 & $03^{\circ} 46.244^{\prime} \mathrm{S} 128^{\circ} 08.971^{\prime} \mathrm{E}$ & 30 & Koloni 6 & T. fuscobalteata & 1 \\
\hline & 20 & $03^{\circ} 46.242^{\prime} \mathrm{S} 128^{\circ} 08.973^{\prime} \mathrm{E}$ & 25 & Koloni 7 & T. sapiens & 1 \\
\hline \multirow[t]{3}{*}{ Seri } & 21 & $03^{\circ} 45.061^{\prime} \mathrm{S} 128^{\circ} 09.368^{\prime} \mathrm{E}$ & 37 & Koloni 8 & T. fuscobalteata & 1 \\
\hline & 22 & $03^{\circ} 44.910^{\prime} \mathrm{S} 128^{\circ} 09.774^{\prime} \mathrm{E}$ & 35 & Koloni 9 & T. fuscobalteata & 1 \\
\hline & 23 & $03^{\circ} 44.910^{\prime} \mathrm{S} 128^{\circ} 09.775^{\prime} \mathrm{E}$ & 35 & Koloni 10 & T. fuscobalteata & 1 \\
\hline \multicolumn{7}{|c|}{ C. Pulau Haruku (PH) } \\
\hline \multirow[t]{3}{*}{ Haruku } & 24 & $03^{\circ} 36.069^{\prime} \mathrm{S} 128^{\circ} 25.337^{\prime} \mathrm{E}$ & 6 & Koloni 1 & T. sapiens & 1 \\
\hline & 25 & $03^{\circ} 36.182^{\prime} \mathrm{S} 128^{\circ} 25.132^{\prime} \mathrm{E}$ & 4 & Koloni 2 & T. fuscobalteata & 1 \\
\hline & 26 & $03^{\circ} 36.238^{\prime} \mathrm{S} 128^{\circ} 25.137^{\prime} \mathrm{E}$ & 6 & Koloni 3 & T. fuscobalteata & 1 \\
\hline \multirow[t]{2}{*}{ Oma } & 27 & $128^{\circ} 33.327^{\prime} \mathrm{S} 128^{\circ} 25.865^{\prime} \mathrm{E}$ & 10 & Koloni 4 & T. fuscobalteata & 1 \\
\hline & 28 & $128^{\circ} 33.327^{\prime} \mathrm{S} 128^{\circ} 25.869^{\prime} \mathrm{E}$ & 10 & Koloni 5 & T. fuscobalteata & 1 \\
\hline \multirow[t]{2}{*}{ Hulaliu } & 29 & $03^{\circ} 34.245^{\prime} \mathrm{S} 128^{\circ} 33.234^{\prime} \mathrm{E}$ & 5 & Koloni 6 & T. fuscobalteata & 1 \\
\hline & 30 & $03^{\circ} 33.136^{\prime} \mathrm{S} 128^{\circ} 33.535^{\prime} \mathrm{E}$ & 18 & Koloni 7 & T. fuscobalteata & 1 \\
\hline
\end{tabular}


Tabel 1. Lokasi pengambilan sampel dan jumlah koloni lebah tanpa sengat di lima pulau di Kepulauan Maluku (Lanjutan...)

\begin{tabular}{|c|c|c|c|c|c|c|}
\hline Desa & Koloni & Titik GPS & $\begin{array}{l}\text { Ketinggian } \\
\text { (m dpl) }\end{array}$ & $\begin{array}{l}\text { Nomor } \\
\text { koloni }\end{array}$ & Spesies & $\begin{array}{c}\text { Total } \\
\text { koloni }\end{array}$ \\
\hline \multicolumn{7}{|c|}{ D. Pulau Saparua (PSa) } \\
\hline \multirow[t]{2}{*}{ Paperu } & 32 & $03^{\circ} 35.595^{\prime} \mathrm{S} 128^{\circ} 39.701^{\prime} \mathrm{E}$ & 19 & Koloni 1 & T. fuscobalteata & 1 \\
\hline & 33 & $03^{\circ} 36.495^{\prime} \mathrm{S} 128^{\circ} 40.501^{\prime} \mathrm{E}$ & 18 & Koloni 2 & T. fuscobalteata & 1 \\
\hline \multirow[t]{3}{*}{ Tuhaha } & 34 & $03^{\circ} 32.081^{\prime} \mathrm{S} 128^{\circ} 41.442^{\prime} \mathrm{E}$ & 9 & Koloni 3 & T. fuscobalteata & 1 \\
\hline & 35 & $03^{\circ} 34.070^{\prime} \mathrm{S} 128^{\circ} 40.429^{\prime} \mathrm{E}$ & 9 & Koloni 4 & T. fuscobalteata & 1 \\
\hline & 36 & $03^{\circ} 32.072^{\prime} \mathrm{S} 128^{\circ} 41.396^{\prime} \mathrm{E}$ & 8 & Koloni 5 & T. fuscobalteata & 1 \\
\hline \multirow[t]{3}{*}{ Ullath } & 37 & $03^{\circ} 36.251^{`} \mathrm{~S} 128^{\circ} 42.831^{`} \mathrm{E}$ & 3 & Koloni 6 & T. fuscobalteata & 1 \\
\hline & 38 & $03^{\circ} 36.251^{\prime} \mathrm{S} 128^{\circ} 42.832^{\prime} \mathrm{E}$ & 3 & Koloni 7 & T. fuscobalteata & 1 \\
\hline & 39 & $03^{\circ} 36.251^{\prime} \mathrm{S} 128^{\circ} 42.834^{\prime} \mathrm{E}$ & 3 & Koloni 8 & T. fuscobalteata & 1 \\
\hline \multicolumn{7}{|c|}{ E. Pulau Nusalaut (PN) } \\
\hline \multirow[t]{2}{*}{ Nalahia } & 40 & $03^{\circ} 39.643^{`} \mathrm{~S} 128^{\circ} 46.712^{`} \mathrm{E} / 37$ & 37 & Koloni 1 & T. fuscobalteata & 1 \\
\hline & 41 & $03^{\circ} 40.103^{\prime} \mathrm{S} 128^{\circ} 46.694^{\prime} \mathrm{E}$ & 43 & Koloni 2 & T. fuscobalteata & 1 \\
\hline \multirow[t]{2}{*}{ Ameth } & 42 & $03^{\circ} 38.934^{\prime} \mathrm{S} 128^{\circ} 48.311^{\prime} \mathrm{E}$ & 1 & Koloni 3 & T. fuscobalteata & 1 \\
\hline & 43 & $03^{\circ} 38.923^{\prime} \mathrm{S} 128^{\circ} 48.290^{\prime} \mathrm{E}$ & 1 & Koloni 4 & T. fuscobalteata & 1 \\
\hline \multirow[t]{2}{*}{ Akoon } & 44 & $03^{\circ} 40.515^{`} \mathrm{~S} 128^{\circ} 48.666^{\circ} \mathrm{E}$ & 8 & Koloni 5 & T. fuscobalteata & 1 \\
\hline & 45 & $03^{\circ} 40.524^{\prime} \mathrm{S} 128^{\circ} 48.602^{\prime} \mathrm{E}$ & 12 & Koloni 6 & T. fuscobalteata & 1 \\
\hline
\end{tabular}
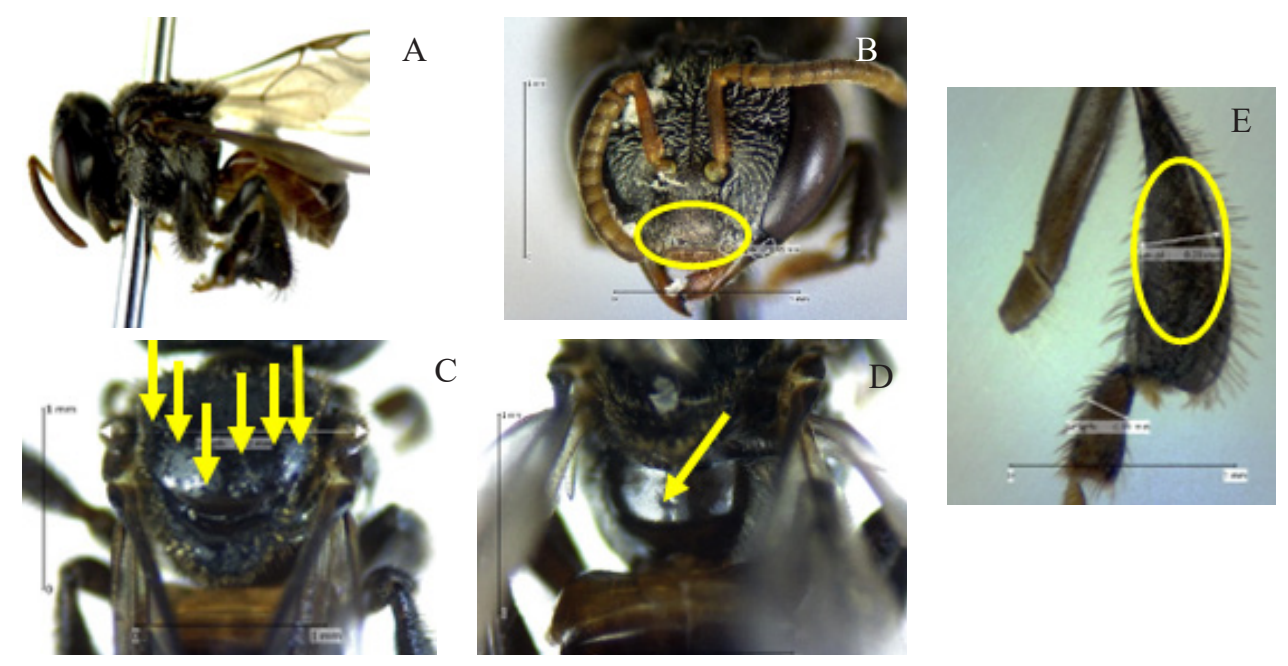

Gambar 1. Karakter morfologi spesies Tetragonula fuscobalteata di Kepulauan Maluku. A: tubuh lengkap; B: bagian clypeus; C: area G1-G2-G3 pada mesoscutum; D: propodeum tidak berambut; E: tungkai dengan rambut pulmose.

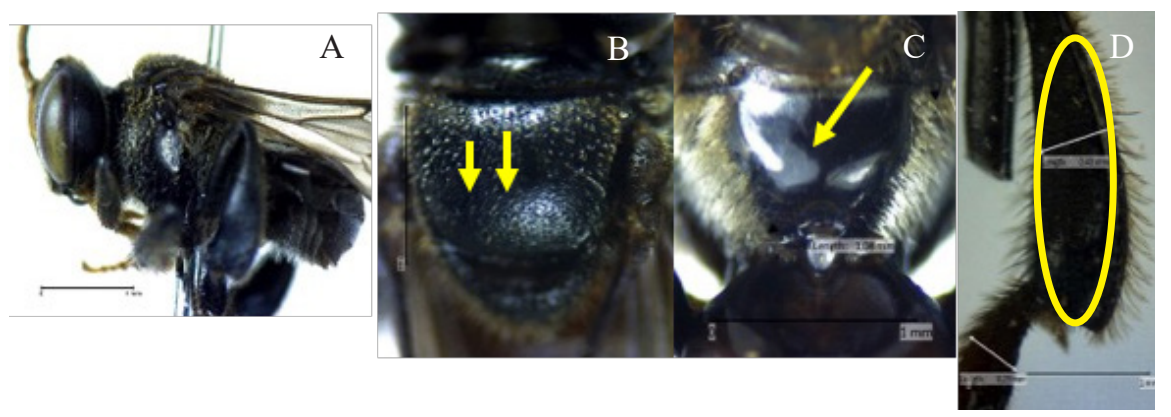

Gambar 2. Karakter morfologi spesies Tetragonula sapiens di Kepulauan Maluku. A: tubuh lengkap; B: area G1-G2 pada mesocutum; C: propodeum tidak berambut; D: tungkai dengan rambut pulmose. 
sama dengan karakter T. fuscobalteata di Sumatera (Sakagami et al. 1990).

Dua belas parameter morfometrik antara T. fuscobalteata dan $T$. sapiens menunjukkan adanya perbedaan yang nyata (Uji Mann-Whitney, $\mathrm{P}<0,05$ ) (Tabel 3). T. sapiens secara nyata memiliki ukuran morfometrik yang lebih besar dibandingkan dengan T. fuscobalteata. Ukuran panjang tubuh $T$. fuscobalteata dari 40 koloni ( $\mathrm{n}=200$ individu) adalah 2,8-3,2 $\mathrm{mm}$ (rata-rata $3,06 \pm 0,28)$, sedangkan $T$. sapiens dari 5 koloni $(\mathrm{n}=25$ individu) memiliki panjang 3,6-3,7 mm (rata-rata 3,67 $\pm 0,11$ ) (Tabel 3, 4 dan 5). Hasil pengukuran panjang tubuh yang berbeda antar

Tabel 2. Perbandingan karakter morfologi Tetragonula fuscobalteata dan T. sapiens berdasarkan Sakagami et al. (1990) (A), Dollin et al. (1997) (B), dan Smith (2012) (C)

\begin{tabular}{|c|c|c|}
\hline Karakter & T. fuscobalteata (A, B, C) & T. sapiens $(\mathrm{B})$ \\
\hline Warna tubuh & $\begin{array}{l}\text { Bicolorous (hitam dengan } \\
\text { abdomen kekuningan) }\end{array}$ & Dominan hitam \\
\hline Toraks & Hitam & Hitam \\
\hline Mesonotum & $\begin{array}{l}\text { Terdapat } 6 \text { hair bands dengan } \\
\text { bagian scutal glabrous }(\mathrm{G}) \text { : G1, } \\
\text { G2, dan G3 sangat jelas }\end{array}$ & $\begin{array}{l}\text { Scutal glabrous (G) kurang jelas } \\
\text { dibandingkan dengan T. fuscobalteata. } \\
\text { G1: lebih sempit namun jelas, G2: ada } \\
\text { namun kurang jelas, G3: tidak ada }\end{array}$ \\
\hline Scutellum & Menonjol melewati propodeum & Menonjol melewati propodeum \\
\hline Bagian tengah Propodeum & Tidak berambut dan mengkilap & Tidak berambut dan mengkilap \\
\hline Abdomen & $\begin{array}{l}\text { Tergit } 1-2 \text { kekuningan atau } \\
\text { coklat terang, } 3-6 \text { coklat gelap }\end{array}$ & Tergit $1-6$ hitam \\
\hline Warna sayap depan & Transparan & Transparan \\
\hline Jumlah Hammuli & Lima & Lima \\
\hline Rambut-rambut di bagian hind tibia & Pulmose (bercabang) & Pulmose (bercabang) \\
\hline $\begin{array}{l}\text { Elliptical disc pada bagian dalam } \\
\text { basitarsus }\end{array}$ & Ada & Ada \\
\hline Panjang sayap depan dengan tegula & $3,3-3,4 \mathrm{~mm}$ & $4,2-4,4 \mathrm{~mm}$ \\
\hline
\end{tabular}

Tabel 3. Perbandingan parameter morfometrik antara Tetragonula fuscobalteata dan T. sapiens

\begin{tabular}{lccc}
\hline Parameter morfometrik $(\mathrm{mm})$ & T. fuscobalteata & T. sapiens & Nilai P (Uji Mann Whitney) \\
\hline PT & $3,06 \pm 0,28$ & $3,67 \pm 0,11$ & $<0,001^{*}$ \\
LT & $1,39 \pm 0,08$ & $1,81 \pm 0,05$ & $<0,001^{*}$ \\
LFd & $0,10 \pm 0,01$ & $0,13 \pm 0,01$ & $<0,001^{*}$ \\
LJM & $1,02 \pm 0,03$ & $1,23 \pm 0,18$ & $<0,001^{*}$ \\
LG & $0,22 \pm 0,03$ & $0,29 \pm 0,05$ & $<0,001^{*}$ \\
JM & $0,02 \pm 0,01$ & $0,03 \pm 0,01$ & $0,019^{*}$ \\
PM & $1,17 \pm 0,07$ & $1,44 \pm 0,09$ & $<0,001^{*}$ \\
PP & $0,83 \pm 0,08$ & $1,11 \pm 0,08$ & $<0,001^{*}$ \\
PSd & $3,19 \pm 0,21$ & $3,88 \pm 0,07$ & $<0,001^{*}$ \\
PSb & $2,22 \pm 0,11$ & $2,72 \pm 0,30$ & $<0,001^{*}$ \\
LTb & $0,39 \pm 0,05$ & $0,47 \pm 0,03$ & $<0,001^{*}$ \\
LBb & $0,21 \pm 0,02$ & $0,29 \pm 0,03$ & $<0,001^{*}$ \\
\hline
\end{tabular}

PT: Panjang tubuh; LT: Lebar toraks; LFd: Lebar flagelomer kedua; LJM: Lebar jarak antar mata; LG: Lebar gena; JM: Jarak malar; PM: Panjang mesonotum; PP: Panjang propodeum; PSd: Panjang sayap depan dengan tegula; PSd: Panjang sayap depan; PSb: Panjang sayap belakang; LTb: Lebar tibia belakang; LBb: Lebar basitarsus belakang. Tanda $\left({ }^{*}\right)$ menunjukan ada pengaruh yang signifikan dengan nilai $\mathrm{P}<0,05$. 
Tabel 4. Perbandingan parameter morfometrik dari Tetragonula fuscobalteata antar pulau

\begin{tabular}{|c|c|c|c|c|c|c|}
\hline \multirow{2}{*}{$\begin{array}{l}\text { Parameter } \\
\text { morfometrik } \\
(\mathrm{mm})\end{array}$} & \multicolumn{5}{|c|}{ Pulau (Rerata \pm SB) } & \multirow{2}{*}{$\begin{array}{c}\text { Nilai P } \\
\text { (Uji Kruskal } \\
\text { Wallis) }\end{array}$} \\
\hline & PSe & PA & PH & $\mathrm{PSa}$ & PN & \\
\hline PT & $3,21 \pm 0,38$ & $3,00 \pm 0,21$ & $3,12 \pm 0,19$ & $3,00 \pm 0,26$ & $2,86 \pm 0,17$ & $<0,001^{*}$ \\
\hline LT & $1,34 \pm 0,13$ & $1,41 \pm 0,02$ & $1,45 \pm 0,02$ & $1,40 \pm 0,04$ & $1,38 \pm 0,03$ & $<0,001 *$ \\
\hline $\mathrm{LFd}$ & $0,10 \pm 0,01$ & $0,10 \pm 0,01$ & $0,11 \pm 0,01$ & $0,10 \pm 0,01$ & $0,10 \pm 0,01$ & $<0,001^{*}$ \\
\hline LJM & $1,01 \pm 0,03$ & $1,03 \pm 0,01$ & $1,04 \pm 0,02$ & $1,02 \pm 0,02$ & $1,01 \pm 0,02$ & $<0,001^{*}$ \\
\hline LG & $0,22 \pm 0,04$ & $0,20 \pm 0,05$ & $0,22 \pm 0,03$ & $0,22 \pm 0,03$ & $0,23 \pm 0,02$ & 0,131 \\
\hline $\mathrm{JM}$ & $0,02 \pm 0,00$ & $0,02 \pm 0,00$ & $0,02 \pm 0,01$ & $0,02 \pm 0,01$ & $0,03 \pm 0,00$ & $<0,001^{*}$ \\
\hline PM & $1,15 \pm 0,09$ & $1,14 \pm 0,07$ & $1,21 \pm 0,05$ & $1,19 \pm 0,05$ & $1,18 \pm 0,03$ & $<0,001^{*}$ \\
\hline PP & $0,83 \pm 0,09$ & $0,88 \pm 0,05$ & $0,86 \pm 0,03$ & $0,84 \pm 0,06$ & $0,72 \pm 0,03$ & $<0,001^{*}$ \\
\hline PSd & $3,09 \pm 0,34$ & $3,23 \pm 0,11$ & $3,29 \pm 0,08$ & $3,24 \pm 0,08$ & $3,17 \pm 0,07$ & $<0,001 *$ \\
\hline $\mathrm{PSb}$ & $2,21 \pm 0,17$ & $2,23 \pm 0,07$ & $2,31 \pm 0,04$ & $2,22 \pm 0,06$ & $2,17 \pm 0,05$ & $<0,001^{*}$ \\
\hline $\mathrm{LTb}$ & $0,34 \pm 0,04$ & $0,37 \pm 0,03$ & $0,41 \pm 0,02$ & $0,41 \pm 0,03$ & $0,46 \pm 0,01$ & $<0,001^{*}$ \\
\hline $\mathrm{LBb}$ & $0,19 \pm 0,02$ & $0,21 \pm 0,01$ & $0,23 \pm 0,02$ & $0,22 \pm 0,01$ & $0,23 \pm 0,01$ & $<0,001^{*}$ \\
\hline
\end{tabular}

Singkatan paramater morfometrik dan tanda (*) mengacu pada keterangan di Tabel 3. PSe: Pulau Seram; PA: Pulau Ambon; PH: Pulau Haruku; PSa: Pulau Saparua; PN: Pulau Nusalaut.

Tabel 5. Perbandingan parameter morfometrik dari Tetragonula sapiens antar pulau

\begin{tabular}{lcccc}
\hline Parameter & \multicolumn{3}{c}{ Pulau (Rerata \pm SB) } & $\begin{array}{c}\text { Nilai P } \\
\text { morfometrik }(\mathrm{mm})\end{array}$ \\
\cline { 2 - 4 } (Uji Kruskal Wallis) \\
\hline PT & PSe & PA & PH & 0,262 \\
LT & $3,73 \pm 0,05$ & $3,67 \pm 0,11$ & $3,62 \pm 0,13$ & $0,021^{*}$ \\
LFd & $1,81 \pm 0,09$ & $1,83 \pm 0,04$ & $1,76 \pm 0,03$ & 0,631 \\
LJM & $0,14 \pm 0,01$ & $0,13 \pm 0,01$ & $0,13 \pm 0,01$ & 0,177 \\
LG & $1,08 \pm 0,40$ & $1,28 \pm 0,02$ & $1,26 \pm 0,01$ & 0,227 \\
JM & $0,30 \pm 0,06$ & $0,27 \pm 0,04$ & $0,32 \pm 0,04$ & 0,090 \\
PM & $0,02 \pm 0,01$ & $0,03 \pm 0,00$ & $0,03 \pm 0,01$ & $0,045^{*}$ \\
PP & $1,51 \pm 0,13$ & $1,45 \pm 0,08$ & $1,36 \pm 0,05$ & $0,003^{*}$ \\
PSd & $1,21 \pm 0,11$ & $1,10 \pm 0,04$ & $1,04 \pm 0,02$ & 0,723 \\
PSb & $3,90 \pm 0,04$ & $3,88 \pm 0,09$ & $3,87 \pm 0,04$ & 0,506 \\
LTb & $2,80 \pm 0,61$ & $2,73 \pm 0,22$ & $2,62 \pm 0,05$ & 0,798 \\
LBb & $0,47 \pm 0,04$ & $0,47 \pm 0,03$ & $0,48 \pm 0,02$ & 0,072 \\
\hline SB
\end{tabular}

Singkatan paramater morfometrik dan tanda (*) mengacu pada keterangan di Tabel 3. PSe: Pulau Seram; PA: Pulau Ambon; PH: Pulau Haruku.

spesies digambarkan pada grafik NMDS dengan adanya pemisahan grup antara T. fuscobalteata dan T. sapiens (Gambar 3, ANOSIM, P <0,001).

\section{Sebaran koloni lebah tanpa sengat pada Kepulauan Maluku}

Hasil penemuan sebaran koloni T. fuscobalteata dan T. sapiens dari penelitian ini menambah data sebaran spesies Tetragonula di Indonesia khususnya di Kepulauan Maluku (Tabel 6). Area persebaran T. fuscobalteata di Kepulauan Maluku lebih luas dibandingkan dengan T. sapiens (Gambar 16
4). T. fuscobalteata yang ditemukan sebanyak 40 total koloni pada lima pulau koleksi (Pulau Seram, Ambon, Haruku, Saparua, dan Nusalaut), sedangkan 5 koloni $T$. sapiens ditemukan di Desa Waesamu, Pulau Seram (koloni 5), Desa Hattu dan Desa Airlouw, Pulau Ambon (koloni 2, 4, dan 7) dan Desa Haruku, Pulau Haruku (koloni 1) (Tabel 1).

\section{Perbandingan morfometrik spesies lebah tanpa sengat antar pulau}

T. fuscobalteata yang ditemukan pada lima pulau (Pulau Seram, Ambon, Haruku, Saparua, 


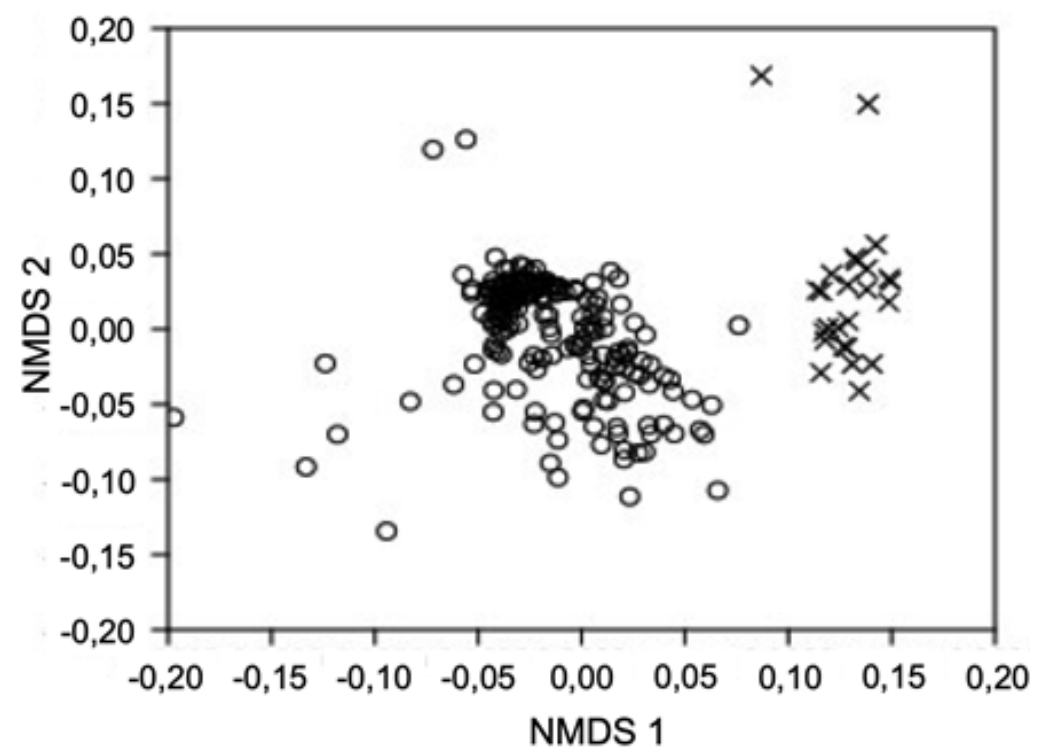

Gambar 3. Ordinasi non-metric multidimensional Scaling (NMDS) pada Tetragonula fuscobalteata dan T. sapiens berdasarkan data pengukuran 12 karakter morfometrik (stress $=0,231)$. Tanda $\mathrm{O}$ menunjukkan T. fuscobalteata dan tanda X menunjukkan koloni T. sapiens.

Tabel 6. Sebaran spesies lebah tanpa sengat Tetragonula di Indonesia berdasarkan Sakagami et al. (1990) (x), Dollin et al. (1997) (o), Rasmussen (2008) (+), Kahono et al. (2018) (-), dan studi ini (s)

\begin{tabular}{|c|c|c|c|c|c|c|}
\hline Nama spesies & Sumatera & Jawa & Kalimantan & Sulawesi & Maluku & Papua \\
\hline Tetragonula biroi (Friese) & & & & & & +- \\
\hline T. clypearis (Friese) & & & & o & $0-$ & $0+$ \\
\hline T. drescheri (Schwarz) & $x+-$ & $x+-$ & $x+-$ & & & \\
\hline T. fuscobalteata (Cameron) & xo+- & $x$ & x o - & +- & $\mathrm{s}$ & \\
\hline T. geissleri (Cockerell) & & & $\mathrm{x}-$ & & & \\
\hline T. laeviceps (Smith) & xo+- & xo+ - & $x+-$ & - & - & + \\
\hline T. melanocephala (Gribodo) & & & $x+-$ & & & \\
\hline T. melina (Gribodo) & $x+-$ & & $x+-$ & & & \\
\hline T. minangkabau (Sakagami \& Inoue) & $x+-$ & & & & & \\
\hline T. reepeni (Friese) & $x+-$ & & $\mathrm{x}-$ & & & \\
\hline T. sapiens (Cockerell) & & & & & $o+-s$ & o- \\
\hline T. sarawakensis (Schwarz) & & & $\mathrm{x}-$ & & & \\
\hline
\end{tabular}

dan Nusalaut) memiliki variasi morfometrik yang berbeda-beda (Gambar 5, ANOSIM, P < 0,001). Koloni T. fuscobalteata yang ditemukan pada Pulau Seram (PSe) lebih tinggi variasinya dibandingkan dengan keempat pulau lainnya yang cenderung lebih mengelompok. Sebelas dari 12 parameter morfometrik (panjang tubuh, lebar toraks, lebar flagelomer kedua, lebar jarak antar mata, jarak malar, panjang mesonotum, panjang propodeum, panjang sayap depan, panjang sayap belakang, lebar tibia belakang, dan lebar basitarsus belakang) dari $T$. fuscobalteata menunjukkan adanya perbedaan yang nyata antar pulau (Tabel
4, uji Kruskall Wallis, $\mathrm{P}<0,05)$. Hanya parameter lebar gena (LG) T. fuscobalteata yang tidak menunjukkan perbedaan nyata antar pulau.

T. fuscobalteata pada Pulau Seram dan Pulau Ambon mempunyai hanya satu parameter morfometrik terbesar, berturut-turut panjang tubuh dan panjang propodeum. Tujuh parameter morfometrik (lebar toraks, lebar flagelomer kedua, lebar jarak antar mata, panjang mesonotum, panjang sayap depan, panjang sayap belakang dan lebar basitarsus belakang) dari T. fuscobalteata pada Pulau Haruku memiliki ukuran terbesar dibandingkan dengan keempat pulau lain. Ukuran 
ketiga parameter morfometrik (jarak malar, lebar tibia belakang, dan lebar basitarsus belakang) pada Pulau Nusalaut lebih besar daripada pulau lain.

Similaritas karakter morfometrik $T$. sapiens terlihat lebih tersebar antar tiga pulau (Gambar 6, ANOSIM, $\mathrm{P}<0,05)$. Hanya Pulau Haruku yang menunjukkan adanya pola berkumpul dengan similaritas yang tergolong lebih tinggi. Variasi morfometrik T. sapiens di Pulau Ambon lebih tinggi daripada koloni spesies yang sama pada
Pulau Seram dan Haruku. Hanya tiga parameter morfometrik (lebar toraks, panjang mesonotum, dan panjang propodeum) yang menunjukkan perbedaan yang nyata antara tiga pulau (Tabel 5, uji Kruskall Wallis, $\mathrm{P}<0,05)$. Lebar toraks dari T. sapiens dengan ukuran terbesar ditemukan pada Pulau Ambon, sedangkan dua parameter morfometrik lainnya (panjang mesonotum dan panjang propodeum) ditemukan dengan ukuran paling besar pada T. sapiens di Pulau Seram.

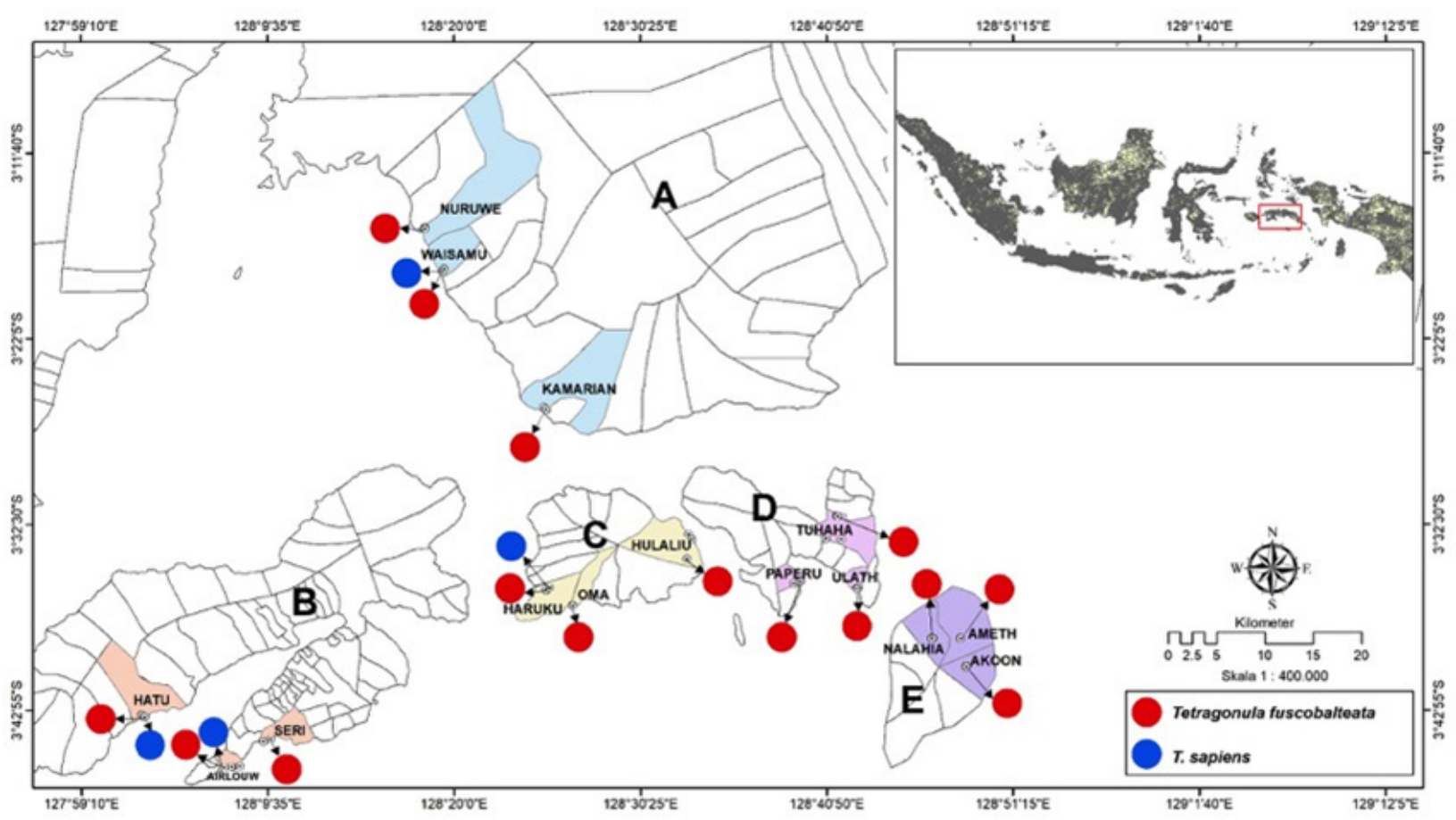

Gambar 4. Sebaran spesies lebah tanpa sengat yang berasal dari Kepulauan Maluku. A. Pesisir Seram Barat; B: Pulau Ambon; C: Pulau Haruku; D: Pulau Saparua; dan E: Pulau Nusalaut.

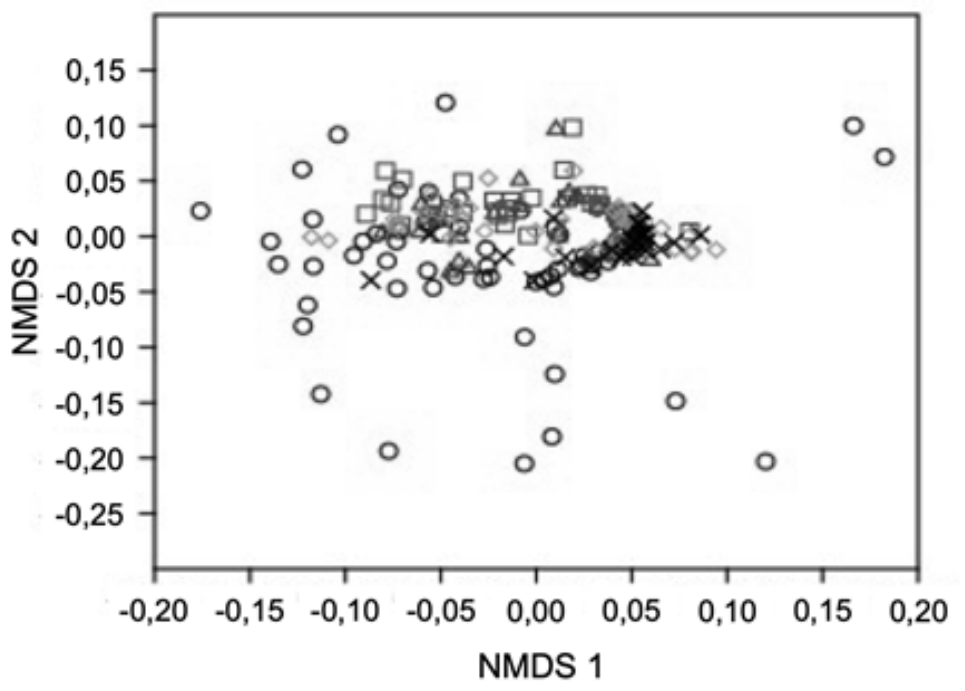

Gambar 5. Ordinasi non-metric multidimensional scaling (NMDS) pada Tetragonula fuscobalteata di lima pulau berdasarkan data pengukuran 12 karakter morfometrik (stress $=0,270$ ). O: Pulau Seram; $\Delta$ : Pulau Ambon; $\square$ : Pulau Haruku; $\diamond$ : Pulau Saparua; dan x: Pulau Nusalaut. 


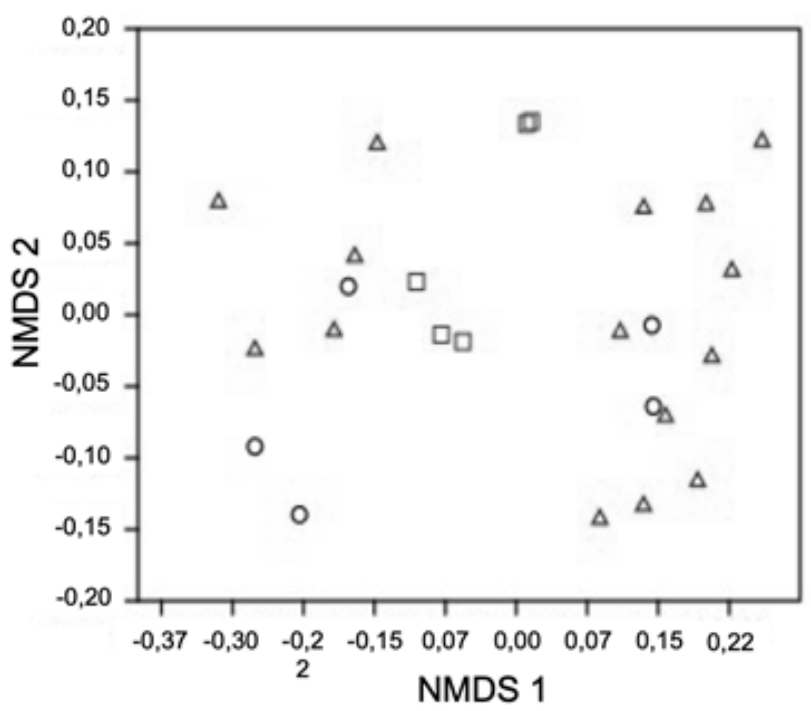

Gambar 6. Ordinasi non-metric multidimensional scaling (NMDS) pada Tetragonula sapiens di tiga pulau berdasarkan data pengukuran 12 karakter morfometrik $($ stress $=0,134)$. O: Pulau Seram; $\Delta$ : Pulau Ambon; 口: Pulau Haruku.

\section{PEMBAHASAN}

Spesies lebah tanpa sengat yang ditemukan pada penelitian ini merupakan catatan penemuan persebaran terbaru untuk spesies T. fuscobalteata di Kepulauan Maluku. Selain itu, data ini memperlihatkan sebaran T. fuscobalteata dan T. sapiens secara spesifik pada Pulau Seram, Ambon, Haruku, Saparua, dan Nusalaut. Penemuan sebelumnya di Kepulauan Maluku tercatat ada tiga spesies, yaitu T. clypearis, T. sapiens, dan T. laeviceps (Dollin et al. 1997; Rasmussen 2008; Kahono et al. 2018), namun tidak tercatat secara spesifik persebaran di pulau-pulau di Maluku. Hanya T. clypearis dan T. laeviceps yang tercatat ditemukan di Pulau Ambon (Smith 1859; Dollin et al. 1997; Kahono et al. 2018). Penelitian ini menambahkan pengetahuan baru bahwa Kepulauan Maluku bukan hanya memiliki lebah tanpa sengat dari tiga spesies $T$. clypearis, T. laeviceps, dan $T$. sapiens, tetapi juga spesies T. fuscobalteata yang pada penelitian ini ditemukan di lima pulau. Hasil ini juga menambahkan sebaran distribusi dari $T$. fuscobalteata yang awalnya hanya tercatat di tiga pulau di Indonesia, yaitu Sumatra, Kalimantan, dan Sulawesi (Sakagami et al. 1990; Rasmussen 2008; Kahono et al. 2018) (Tabel 6). Selain itu, T. sapiens juga tidak hanya ditemukan di Pulau Ambon saja, tetapi dapat ditemukan di Pulau Seram dan Haruku sehingga menambah data sebaran lebah tanpa sengat di Kepulauan Maluku.
Karakter morfometrik panjang tubuh dari $T$. fuscobalteata di Pulau Seram $(3,21 \pm 0,38 \mathrm{~mm})$ dan Pulau Ambon $(3,00+0,21 \mathrm{~mm})$ berukuran lebih besar dibandingkan dengan koloni $T$. fuscobalteata di Pulau Sumatra dan Sulawesi, tetapi lebih kecil dari T. fuscobalteata di Pulau Kalimantan. Panjang tubuh pada T. fuscobalteata asal Sumatra, Kalimantan, dan Sulawesi secara berurutan berukuran 3, 3,60-3,64, dan 2,74 $\pm 0,38$ (mm) (Sakagami et al. 1990; Kerisna et al. 2019; Sayusti et al. 2021). Berbeda halnya di pulau besar, variasi panjang tubuh $T$. fuscobalteata di Pulau Belitung lebih tinggi, yaitu berkisar 2,8-3,6 mm (Azizi et al. 2020). Hal ini menunjukkan bahwa panjang tubuh T. fuscobalteata Kepulauan Maluku memiliki perbedaan dengan T. fuscobalteata di pulau lain di Indonesia dengan rentang ukuran yang lebih kecil, yaitu 2,8-3,2 mm.

Panjang tubuh $T$. sapiens hasil penelitian ini berkisar 3,6-3,7 mm yang sama kisarannya dengan spesies yang sama di Sulawesi, yaitu 3,7 $\pm 0,39$ $\mathrm{mm}$ (Sayusti et al. 2021). Hal yang menarik adalah rentang panjang tubuh $T$. sapiens di Australia lebih besar dibandingkan dengan di Kepulauan Maluku, yaitu 3,6-4,2 mm (Dollin et al. 1997). Selain panjang tubuh, ukuran panjang sayap depan $T$. sapiens di Maluku adalah 3,8-3,9 mm, yang masuk dalam rentang ukuran $3,5-4,5 \mathrm{~mm}$ pada referensi Dollin et al. (1997). Akan tetapi, panjang sayap depan T. sapiens di Kepulauan Maluku berukuran lebih kecil dibandingkan dengan di Australia dan 
Pulau Solomon keduanya ada dalam rentang $4,2-$ 4,5 mm (Dollin et al. 1997).

Ukuran tubuh individu dalam suatu spesies cenderung lebih kecil atau lebih besar bergantung pada sumber daya lingkungan spesies tersebut hidup sesuai dengan evolusi biologi yang terkait ekogeografi (Lokatis \& Jeschke 2018). Hal tersebut berhasil dikemukakan menjadi suatu keteraturan yang disebut island rule atau island effect. Efek pulau pada hewan vertebrata dan avertebrata dapat menunjukkan perbedaan pola yang berbeda-beda. Hewan vertebrata (kadal dan tikus) di pulau umumnya berukuran lebih besar dibandingkan dengan pulau utama (Takada et al. 1994; Hernández-Salinas et al. 2014). Hal ini berbeda dengan yang ditunjukkan oleh beberapa hewan avertebrata yang tidak mengikuti keteraturan tersebut. Morfometrik populasi cacing Lumbricidae di Pulau Aland berbeda dengan populasinya di pulau utama (Estonia, Sweden, dan Findland). Hal ini terlihat pada morfometrik dua spesies cacing Aporrectodea rosea, Octolasion tyrtaeum yang lebih besar dari pulau utama (Terhivuo \& Saura 1997). Ukuran panjang tubuh Apis cerana Fabricius lebih besar di pulau utama yang ukurannya lebih besar (Visayas-Mindanao) dibandingkan dengan pulau kecil di Filipina (Tilde et al. 2000). Pada penelitian ini, jika pulau Seram dikatakan sebagai pulau utama karena pulau terbesar di Kepulauan Maluku maka panjang tubuh dari T. fuscobalteata terbesar yang ditemukan di Pulau Seram memiliki pola, seperti ukuran panjang tubuh A. cerana di Filipina (Tilde et al. 2000). Fenomena yang menarik adalah variasi ukuran panjang tubuh $T$. fuscobalteata sangat tinggi, yaitu panjang tubuh T. fuscobalteata di Pulau Belitung dapat lebih kecil atau lebih besar dari pulau utama (Pulau Sumatra atau Pulau Kalimantan sebagai pulau utama) (Sakagami et al. 1990; Kerisna et al 2019; Azizi et al. 2020). Perbedaan morfometrik panjang tubuh merupakan salah satu bentuk adaptasi lebah terhadap lingkungan (Gaston et al. 2008) yang dapat disebabkan oleh perbedaan lokasi dan sumber makanan (Hamid et al. 2016).

Panjang tubuh lebah tanpa sengat tersebut dapat menjadi salah satu cara sederhana dalam memilih spesies yang akan dibudidayakan (meliponikultur). Ukuran panjang tubuh lebah tanpa sengat yang besar dapat meningkatkan jumlah produksi madu yang dihasilkan, seperti $H$. itama yang menghasilkan jumlah produksi madu, propolis, dan polen lebih banyak daripada T. laeviceps (Priawandiputra et al. 2020; Syafrizal et al. 2020). Perlu penelitian lebih lanjut mengenai hubungan antara karakter morfologi dan morfometrik terhadap parameter meliponikultur. Selain itu, faktor-faktor lainnya juga perlu diteliti, seperti kemampuan adaptasi spesies dan tumbuhan pakan.

Selain parameter panjang tubuh, nilai pengukuran masing-masing parameter morfometrik lainnya dari $T$. fuscobalteata dan $T$. sapiens dengan ukuran terbesar tidak hanya terpusat pada satu populasi pulau saja (Tabel 4 dan 5). Karakter panjang sayap depan dan sayap belakang T. fuscobalteata paling besar ditemukan di Pulau Haruku, sedangkan pada T. sapiens ditemukan pada Pulau Seram. Pola parameter morfometrik lain tidak memiliki kecenderungan yang sama dengan pola karakter morfometik panjang tubuh. Populasi A. cerana di Pulau Palawan (Filipina) memiliki karakter morfometrik (panjang sayap dan tungkai) berbeda dan terpisah dari A. cerana di pulau lain, yaitu Luzon, Mindanao, dan Visayas (Tilde et al. 2000). Hal ini menunjukan adanya variasi ukuran parameter morfometrik yang besar antar pulau.

Sebaran geografis yang luas pada $T$. fuscobalteata dapat menyebabkan tingginya variasi karakteristik morfometrik. Persebaran T. fuscobalteata dapat ditemukan di Thailand, Malaysia, dan Indonesia (Sakagami et al. 1990; Dollin et al. 1997; Kahono et al. 2018, Azizi et al. 2020). Variasi morfometrik T. fuscobalteata di Kepulauan Maluku adalah sangat tinggi terutama di Pulau Seram (PSe) yang merupakan pulau terbesar atau pulau utama di Kepulauan Maluku. Perbedaan karakter morfometrik pada spesies ini antar pulau lainnya menunjukkan adanya perbedaan cara adaptasi kondisi lingkungan di masing-masing pulau.

\section{KESIMPULAN}

Eksplorasi lebah tanpa sengat di Kepulauan Maluku berhasil menemukan dan mengidentifikasi dua spesies, yaitu T. fuscobalteata dan T. sapiens 
dan memperjelas lokasi sebaran pada Pulau Seram, dan empat pulau kecil di sekitarnya, yaitu Pulau Ambon, Haruku, Saparua, dan Nusalaut. Penemuan ini menghasilkan catatan baru T. fuscobalteata di Kepulauan Maluku dan catatan penyebaran $T$. sapiens secara spesifik di kepulauan ini. T. fuscobalteata di Kepulauan Maluku memiliki panjang rata-rata 3,06 $\pm 0,28$ (mm) lebih kecil dari $T$. sapiens dengan panjang rata-rata 3,67 $\pm 0,11(\mathrm{~mm})$. Data morfometrik antar T. fuscobalteata dan T. sapiens menunjukkan perbedaan nyata pada 12 parameter morfometrik $(\mathrm{P}<0,05)$ dan memperlihatkan pemisahan kelompok berdasarkan analisis NMDS. Seluruh parameter morfometrik spesies T. fuscobalteata, kecuali lebar gena menunjukan perbedaan nyata antar lima pulau $(\mathrm{P}<0,05)$ dengan variasi tertinggi pada lebah tanpa sengat di pulau Seram (PSe). T. sapiens yang ditemukan di tiga pulau memiliki tiga parameter morfometrik yang berbeda nyata, yaitu lebar toraks, panjang mesonotum, dan panjang propodeum.

\section{UCAPAN TERIMA KASIH}

Penelitian ini merupakan bagian dari pendanaan oleh Kementrian Riset dan Pedidikan Tinggi di bawah skim penelitian $\mathrm{HIBAH}$ Kompetensi tahun 2017 (No. 011/SP2H/LT/ DRPM/IV/2017) atas nama penulis korespondensi. Ucapan terima kasih disampaikan juga kepada para pihak yang telah mendukung proses sampling lebah tanpa sengat asal Kepulauan Maluku hingga proses penelitian di Divisi Biosistematika dan Ekologi Hewan, Departemen Biologi, FMIPA, IPB University.

\section{DAFTAR PUSTAKA}

Azizi MG, Priawandiputra W, Raffiudin R. 2020. Morphological identification of stingless bees from Belitung. IOP Conference Series Earth \& Environmental Science 457:012011. doi: https:// doi.org/10.1088/1755-1315/457/1/012011.

[BPS] Badan Pusat Statistik Maluku. 2015. Data Luas Wilayah di Maluku. Tersedia pada: https:// maluku.bps.go.id/. [diakses 20 Februari 2020].
Dollin AE, Dollin LJ, Sakagami SF. 1997. Australian stingless bees of the Genus Trigona (Hymenoptera: Apidae). Invertebrate Taxonomy 11:861-896. doi: https://doi.org/10.1071/ IT96020.

Gaston KJ, Chown SL, Evans KL. 2008. Ecogeographical rules: elements of a synthesis. JournalofBiogeography 35:483-500. doi: https:// doi.org/10.1111/j.1365-2699.2007.01772.x.

Hamid SA, Salleh MS, Thevan K, Hashim NA. 2016. Distribution and morphometrical variations of stingless bees (Apidae: Meliponini) in urban and forest areas of Penang Island, Malaysia. Journal of Tropical Resources and Sustainable Science $4: 1-5$.

Hamilton W. 1979. Tectonics of the Indonesian region. USGS Professional Paper 1078: 345. doi: https://doi.org/10.3133/pp1078.

Hammer O, Harper DAT, Ryan PD. 2009. PASTPalaeontological Statistic ver 3.0. Tersedia pada: htttp://folk.uio.no/ohammer/past. [diakses 29 November 2018].

Hernández-Salinas U, Ramírez-Bautista A, Pavón NP, Pacheco LFR. 2014. Morphometric variation in island and mainland populations of two lizard species from the Pacific Coast of Mexico. Revista Chilena de Historia Natural 87:21. doi: https:// doi.org/10.1186/s40693-014-0021-3.

Kahono S, Chantawannakul P, Engel MS. 2018. Social bees and the current status of beekeeping in Indonesia. Di dalam: Chantawannakul P, Williams G, Neumann P (Eds.) Asian Beekeeping in the 21st Century. Springer Verlag. hlm. 287306. doi: https://doi.org/10.1007/978-981-108222-1_13.

Kerisna V, Diba F, Wulandari RC. 2019. Identifikasi jenis lebah Trigona spp. pada zona pemanfaatan hutan desa Menua Sadap Kecamatan Embaloh Hulu Kabupaten Kapuas Hulu. Jurnal Tengkawang 9:82-91.

Laksono P. Raffiudin R. Juliandi B. 2020. Stingless bees Tetragonula laeviceps and T. aff. biroi: geometric morphometry analysis of wing venation variations. IOP Conference Series Earth \& Environmental Science 457:012084. doi: https:// doi.org/10.1088/1755-1315/457/1/012084.

Lohman DJ, Bruyn MD, Page T, Rintelen KV, Hall R, Ng PKL, Shih HT, Carvalho GR, Rintelen TV. 2011. Biogeography of the Indo-Australian archipelago. Annual Review of Ecology, Evolution, and Systematics 42:205-26. doi: https://doi. org/10.1146/annurev-ecolsys-102710-145001.

Lokatis S, Jeschke JM. 2018. The island rule: An assessment of biases and research trends. Journal 
of Biogeography 45:289-303. doi: https://doi. org/10.1111/jbi.13160

Miconos. 2021. Panduan Singkat Penggunaan Image Raster. Tersedia pada: https://www.miconos. co.id/p/tutorial.html. [diakses 12 Mei 2021].

Patmawidjaya T, Subagyo. 2014. Penelitian gaya berat dan geomagnit kepulauan Aru, cekungan wokam. Jurnal Geologi Kelautan 12:1-14. doi: https://doi.org/10.32693/jgk.12.1.2014.241.

Priawandiputra W, Azizi MG, Rismayanti, Djakaria KM, Wicaksono A, Raffiudin R, Atmowidi T, Buchori D. 2020. Panduan Budi Daya Lebah Tanpa Sengat (Stingless bees) di Desa Perbatasan Hutan: Studi di Lubuk Bintialo dan Pangkalan Bulian, Sumatera Selatan. Bogor: ZSL Indonesia.

Rasmussen C. 2008. Catalog of the IndoMalayan/Australasian stingless bees (Hymenoptera: Apidae: Meliponini). Zootaxa 1935:1-80. doi: https://doi.org/10.11646/ zootaxa.1935.1.1.

Roubik DW. 1983. Nest and colony characteristics of stingless bees from Panama. Journal of the Kansas Entomological Society 56:327-355. doi: https://doi.org/10.1017/CBO9780511574641.

Roubik DW. 1989. Ecology and Natural History of Tropical Bees. New York: Cambridge University Press. doi: https://doi.org/10.1017/ CBO9780511574641.

Sakagami SF, Inoue T, Salmah S. 1990. Stingless bees of central Sumatra. Di dalam: Sakagami SF, Ohgushi R, Roubik DW (Eds.) Natural History of Social Wasps and Bees in Equatorial Sumatra. hlm: 125-137. Sapporo: Hokkaido Univ Press.

Sayusti T. Raffiudin R. Kahono S. 2021. Stingless bees (Hymenoptera: Apidae) in South and West Sulawesi, Indonesia: Morphology, nest structure, and molecular characteristics. Journal of Apicultural Research 60:143-156. doi: https:// doi.org/10.1080/00218839.2020.1816272.
Smith F. 1859. Catalogue of Hymenopterous insects collected by Mr. A. R. Wallace at the Islands of Aru and Key. Journal of the Proceedings of the Linnean Society, Zoology 3:132-178. doi: https:// doi.org/10.1111/j.1096-3642.1859.tb00077.x.

Smith DR. 2012. Key to workers of Indo-Malayan stingless bees. For use in the Stingless bees Workshop 1:1-42.

Syafrizal, Ramadhan R, Kusuma IW, Egra S, Shimizu K, Kanzaki M, Arung ET. 2020. Diversity and honey properties of stingless bees from meliponiculture in East and North Kalimantan, Indonesia. Biodiversitas 21:4623-4630. doi: https://doi.org/10.13057/biodiv/d211021.

Takada Y, Yamada H, Tateishi T. 1994. Morphometric variation of Japanese wild mice on islands. Journal of the Mammalogical Society of Japan 19:113-128.

Terhivuo J, Saura A. 1997. Island biogeography of North European parthenogenetic Lumbricidae: I. Clone pool affinities and morphometric differentiation of Åland Populations. Ecography 20:185-196. doi: https://doi. org/10.1111/j.1600-0587.1997.tb00361.x.

Tilde CA. Fuchs S. Koeniger N. Cervancia CR. 2000. Morphometric diversity of Apis cerana Fabr. within the Phillipines. Apidologie 31:249-263. doi: https://doi.org/10.1051/apido:2000120.

Wikramanayake E, Dinerstein E, Loucks CJ. 2001. Terrestrial Ecoregion of the Indo-pacific. Washington DC: Island Press. 